\title{
Kinetics of Z-Phase Precipitation in 9 to 12 pct Cr Steels
}

\section{Danielsen, Hilmar Kjartansson; Nunzio, Paolo Emilio di; Hald, John}

\section{Published in:}

Metallurgical and Materials Transactions A: Physical Metallurgy and Materials Science

Link to article, DOI:

10.1007/s11661-012-1583-9

Publication date:

2013

Document Version

Publisher's PDF, also known as Version of record

Link back to DTU Orbit

Citation (APA):

Danielsen, H. K., Nunzio, P. E. D., \& Hald, J. (2013). Kinetics of Z-Phase Precipitation in 9 to 12 pct Cr Steels. Metallurgical and Materials Transactions A: Physical Metallurgy and Materials Science, 44(5), $2445-2452$. https://doi.org/10.1007/s11661-012-1583-9

\section{General rights}

Copyright and moral rights for the publications made accessible in the public portal are retained by the authors and/or other copyright owners and it is a condition of accessing publications that users recognise and abide by the legal requirements associated with these rights.

- Users may download and print one copy of any publication from the public portal for the purpose of private study or research.

- You may not further distribute the material or use it for any profit-making activity or commercial gain

- You may freely distribute the URL identifying the publication in the public portal 


\title{
Kinetics of Z-Phase Precipitation in 9 to 12 pct Cr Steels
}

\author{
HILMAR K. DANIELSEN, PAOLO EMILIO DI NUNZIO, and JOHN HALD
}

\begin{abstract}
The Z-phase nitride is seen as a detrimental phase in 9 to $12 \mathrm{pct} \mathrm{Cr}$ steels as it is in competition with the beneficial MX particles. Two model steels, with 9 pct $\mathrm{Cr}$ and $12 \mathrm{pct} \mathrm{Cr}$ content, respectively, were designed to study the effect of $\mathrm{Cr}$ on Z-phase precipitation kinetics. The steels were isothermally aged at $873 \mathrm{~K}, 923 \mathrm{~K}$, and $973 \mathrm{~K}\left(600{ }^{\circ} \mathrm{C}, 650{ }^{\circ} \mathrm{C}\right.$, and $\left.700{ }^{\circ} \mathrm{C}\right)$ for up to 30,000 hours in order for Z-phase to replace MX. X-ray diffraction (XRD) analysis of extracted precipitates was used to quantitatively follow the evolution of the nitrides population. It was found that the 12 pct Cr steel precipitated Z-phase 20 to 50 times faster than the 9 pct $\mathrm{Cr}$ steel. Transmission electron microscopy (TEM) was applied to follow the Z-phase precipitation, using energy-dispersive X-ray spectroscopy (EDS) line scans and atomic resolution imaging.
\end{abstract}

DOI: $10.1007 / \mathrm{s} 11661-012-1583-9$

(C) The Minerals, Metals \& Materials Society and ASM International 2013

\section{BACKGROUND}

THE 9 to 12 pct Cr martensitic steels are widely used for power plant applications as they provide a good combination of high-temperature creep properties, oxidation resistance, and low cost. The newest 9 pct $\mathrm{Cr}$ steel grades have allowed operation at supercritical steam conditions up to $873 \mathrm{~K}\left(600{ }^{\circ} \mathrm{C}\right)$ and 300 bar in state-of-the-art power plants. The efficiency of these plants yield savings of about 30 pct in specific $\mathrm{CO}_{2}$ emissions compared to older subcritical plants $(813 \mathrm{~K}$ $\left[540{ }^{\circ} \mathrm{C}\right] / 180$ bar). Higher temperature and pressure conditions $\left(923 \mathrm{~K}\left[650{ }^{\circ} \mathrm{C}\right] / 325\right.$ bar) are sought to increase efficiency, and for this purpose improved 12 pct $\mathrm{Cr}$ steel grades have been extensively tested. However, the high $\mathrm{Cr}$ content has caused microstructural instabilities in the steels for relatively short exposure times (10 kh).

The 9 to 12 pct $\mathrm{Cr}$ martensitic steels rely on precipitate strengthening for long-term creep strength at high temperatures. The prime beneficial precipitates are finely dispersed small MX nitrides, $(\mathrm{V}, \mathrm{Nb}) \mathrm{N}$, which are dimensionally stable at high temperatures. However, they are not thermodynamically stable and are slowly replaced by another nitride called Z-phase with a $\mathrm{Cr}(\mathrm{V}, \mathrm{Nb}) \mathrm{N}$ composition. With time, the Z-phase will fully replace the MX particles, as they contain the same constituents, but this can be a very slow process, measured in years or even decades. As the Z-phase precipitation is very slow, they will appear as few coarse particles, which do not contribute significantly to creep strengthening as opposed to the MX nitrides, resulting in a net loss of creep strength. ${ }^{[1-3]}$ Thus, the long-term creep strengths of these steels are dependent on the

HILMAR K. DANIELSEN, Senior Researcher, is with Mechanical Engineering, Technical University of Denmark (DTU), $2800 \mathrm{Kgs}$ Lyngby, Denmark. Contact e-mail: hkd@mek.dtu.dk PAOLO EMILIO DI NUNZIO, Senior Researcher, is with Centro Sviluppo Materiali S.p.A. (CSM), 00128 Rome, Italy. JOHN HALD, Head, is with DONG Energy, 2820 Gentofte, Denmark.

Manuscript submitted September 10, 2012.

Article published online January 18, 2013
Z-phase being slow to precipitate and not appearing in significant numbers within the lifetime of the power plants. It is now known that this precipitation process is significantly faster in 12 pct $\mathrm{Cr}$ steels, which have been favored for their high oxidation resistance needed in planned future power plants operating at higher temperatures. Thermodynamic modeling has shown the main driving force for Z-phase precipitation to be the $\mathrm{Cr}$ content dissolved in the matrix. ${ }^{[4]}$ Investigations by electron microscopy have revealed the nucleation of Z-phase to be a diffusion of $\mathrm{Cr}$ atoms from the matrix into existing MX particles, physically transforming them into Z-phase. ${ }^{[5]}$ The effects of Z-phase on the creep strength of 12 pct $\mathrm{Cr}$ steels has been well described because of the relatively fast precipitation, but recent investigations of commercial 9 pct $\mathrm{Cr}$ steel grades have indicated that the Z-phase might also affect these steels within their expected service life. ${ }^{[6]}$ As these steels already are extensively used around the world, this could affect the lifetime of existing power plants. The objective of this article has been to quantify the effect of $\mathrm{Cr}$ on the Z-phase precipitation speed in these steels.

\section{EXPERIMENTAL}

Two model alloys with 9 and 12 pet $\mathrm{Cr}$, respectively, were designed with very similar compositions. As the alloys were meant for studying the nitride behavior using X-ray diffraction (XRD) measurements, the aim was to obtain an alloy devoid of other precipitate types. Without overlapping signals from other precipitates, the MX to Z-phase transformation could be followed. Thus, a very low $\mathrm{C}$ content was sought to avoid carbide formations, and elements like $\mathrm{W}$ and Mo were not added to prevent Laves phase from precipitating. A relatively high nickel content was needed to ensure a fully martensitic microstructure in the alloys.

The first alloy, $12 \mathrm{CrVNbN}$, was designed for a fast precipitation of Z-phase using a thermodynamic model, ${ }^{[4]}$ as the precipitation process could otherwise take decades. 
Thus, a 12 pet $\mathrm{Cr}$ alloy was used with additions of $\mathrm{V}, \mathrm{Nb}$, and $\mathrm{N}$ similar to commercial steel grades. This alloy could be used to study the transformation of Z-phase within a reasonable time period. The second alloy, $9 \mathrm{CrVNbN}$, was similar to the first, except 9 pet $\mathrm{Cr}$ was used in this alloy, a similar content to what is found in most commercial steel grades. Thus, by comparing the two alloys, the effect of $\mathrm{Cr}$ on the Z-phase precipitation kinetics could be determined.

The model alloys were produced by vacuum induction melting as $80 \mathrm{~kg}$ ingots; the chemical compositions as determined by X-ray fluorescence spectroscopy are given in Table I. The ingots were hot rolled into 20 -mm-thick plates and subsequently normalized at $1323 \mathrm{~K}\left(1050{ }^{\circ} \mathrm{C}\right)$ for 1 hour, followed by air cooling. Thereafter, they were tempered at $1023 \mathrm{~K}\left(750{ }^{\circ} \mathrm{C}\right)$ for 2 hours, followed by air cooling to obtain a tempered martensite microstructure. The microstructure consists entirely of tempered martensite, no delta ferrite was present, and the average hardness was around $235 \mathrm{HV}_{10}$. After normalizing and tempering, the samples were aged at $873 \mathrm{~K}, 923 \mathrm{~K}$, or $973 \mathrm{~K}\left(600{ }^{\circ} \mathrm{C}, 650{ }^{\circ} \mathrm{C}\right.$, or $\left.700{ }^{\circ} \mathrm{C}\right)$ for up to 30,000 hours in laboratory furnaces flushed with air.

XRD spectra of the precipitated phases were recorded using a Bruker D8 Advance powder diffractometer (Bruker AXS, Karlsruhe, Germany) with $\mathrm{Cu}$ radiation where $\mathrm{Cu}-\mathrm{k} \alpha_{1}$ and $\mathrm{Cu}-\mathrm{k} \alpha_{2}$ components had an intensity ratio of $2: 1$. To avoid interference from matrix reflections, the precipitates were extracted from the bulk by electrolysis in an acidic solution of 5 pet $\mathrm{HCl}$ in 95 pet ethanol, dissolving the matrix while gathering the precipitates by sedimentation. Some of the very small precipitates may not have been fully recovered by the sedimentation process. This could cause an underestimation of especially the VN amount, as they are usually very small.

A Rietveld refinement of the XRD spectra was used to quantify the volume fraction of each phase. By this technique, a set of parameters is refined to minimize the difference between the experimental data and a simulated diffractogram. The model crystal structures of the phases and their chemical compositions as measured by transmission electron microscopy (TEM)-energy-dispersive X-ray spectroscopy (EDS) are taken into account to calculate the absolute diffracted intensities. Then, the algorithm fits the measured spectrum in a given angular range by adjusting the peak shapes according to a theoretical function expressing the line profiles, taking also into account the absorption effects. Taking into account all the possible uncertainties in the different elaboration steps, the total error of the fitting procedure can be estimated to be maximally \pm 3 units of volume percent. Details of the procedure can be found in Reference 7 . In the calculations all precipitates were considered to have constant chemical composition and the crystal structures reported in Reference 7. The absolute intensity of the main reflections of the $\pi$-phase found in $12 \mathrm{CrVNbN}$ alloy at $873 \mathrm{~K}\left(600^{\circ} \mathrm{C}\right)$ were calculated from its typical chemical composition, as measured by EDS, and an estimated lattice parameter of about $0.628 \mathrm{~nm}$.

In the analyzed spectra, the algorithm has been applied to the spectrum obtained by a $\mathrm{Cu}-\mathrm{K} \alpha$ doublet in the range of $2 \theta$ from $35 \mathrm{deg}$ to $47 \mathrm{deg}$, where the majority of the main diffraction peaks of the phases are located.

The morphology and composition of the precipitates in the as-treated and aged samples were investigated with a field emission gun (FEG)-TEM (JEOL 3000F; JEOL Ltd., Tokyo, Japan). Furthermore, high-angle annular dark-field (HAADF) atomic resolution imaging was carried out using a FEI Titan 80-300ST TEM (FEI Company, Hillsboro, OR) with CEOS CESCOR probe spherical aberration corrector. All TEM observations were carried out on carbon extraction replicas. The replicas were prepared by a chemical etch with Vilella's reagent ( 1 pet picric acid and 5 pct hydrochloric acid in ethanol).

Identification of the precipitates in TEM investigations was done on the basis of EDS composition measurements of the metallic elements: Particles with $[\mathrm{V}]+[\mathrm{Nb}] \geq 70$ at. pct were identified as MX. Two separate populations of MX nitrides were found, V-rich and $\mathrm{Nb}$-rich, and particles with $\mathrm{Nb}$ rich cores and $\mathrm{V}$ rims were not uncommon. The $\mathrm{MX}$-type precipitates $\mathrm{VN}$ and $\mathrm{NbN}$ have a $\mathrm{NaCl}$-type crystal structure (facecentered cubic lattice of metal atoms with octahedral interstitial sites occupied by $\mathrm{N}$ ), with lattice parameters of 0.413 and $0.439 \mathrm{~nm}$, respectively. However, because the compositions of the MX precipitates found in the model alloys are rather $(\mathrm{V}, \mathrm{Nb}) \mathrm{N}$ and $(\mathrm{Nb}, \mathrm{V}) \mathrm{N}$, the lattice parameters of both precipitate types are closer to each other.

$\mathrm{M}_{2} \mathrm{X}$ usually have a $\mathrm{Cr}_{2} \mathrm{~N}$ composition with a hexagonal crystal structure and lattice parameters $a=$ $0.481 \mathrm{~nm}$ and $c=0.448 \mathrm{~nm}$. $\mathrm{Cr}_{2} \mathrm{~N}$ nitrides could be identified by the following compositional criterion: $[\mathrm{Cr}] \geq 70$ at. pct of the metallic elements, the real composition being $(\mathrm{Cr}, \mathrm{V})_{2} \mathrm{~N}$. The $\mathrm{V}$ content does not affect the lattice parameter as $\mathrm{Cr}$ and $\mathrm{V}$ atoms are similar in size.

The modified Z-phase, $\mathrm{Cr}(\mathrm{V}, \mathrm{Nb}) \mathrm{N}$, was identified by the compositional relationship $[\mathrm{Fe}]+[\mathrm{Cr}] \approx[\mathrm{V}]+$ $[\mathrm{Nb}]$, where $45<[\mathrm{Fe}]+[\mathrm{Cr}] \leq 65$ at. pct. Previous work has shown that the Z-phase does not nucleate in the matrix as most precipitates do, but rather it forms by $\mathrm{Cr}$ diffusion from the matrix into existing MX particles, which are then transformed compositionally and

Table I. Composition of the Model Alloys in wt pet, Balance Fe

\begin{tabular}{lrccccccc}
\hline & $\mathrm{Cr}$ & $\mathrm{V}$ & $\mathrm{Nb}$ & $\mathrm{N}$ & $\mathrm{C}$ & $\mathrm{Ni}$ & $\mathrm{Mn}$ & $\mathrm{Si}$ \\
\hline $12 \mathrm{CrVNbN}$ & 11.85 & 0.183 & 0.076 & 0.061 & 0.0048 & 1.29 & 0.32 & 0.40 \\
$9 \mathrm{CrVNbN}$ & 9.11 & 0.207 & 0.080 & 0.059 & 0.0040 & 1.27 & 0.34 & 0.41 \\
\hline
\end{tabular}


crystallographically into Z-phase. ${ }^{[5,8,9]}$ This results in Z-phase having two different crystal structures, which can coexist in a single precipitate particle. ${ }^{[10]}$ The primary Z-phase crystal structure is tetragonal with lattice parameters of $a=0.286 \mathrm{~nm}$ and $c=0.739 \mathrm{~nm}$, and it is likely the most thermodynamically stable. The secondary Z-phase crystal structure has a $\mathrm{NaCl}$ type lattice resembling that of the MX and is probably metastable. It has a slightly lower lattice parameter $(a=0.404 \mathrm{~nm})$ than the V-rich MX which it transforms from, as only half of the interstitial sites would be occupied by $\mathrm{N}$.

\section{RESULTS AND DISCUSSION}

After normalizing and tempering, both alloys contained only $\mathrm{M}_{2} \mathrm{X}$ and $\mathrm{MX}$ nitrides, while the Z-phase precipitates during the annealing. TEM investigations were mainly carried out on $12 \mathrm{CrVNbN}$ exposed at $923 \mathrm{~K}\left(650^{\circ} \mathrm{C}\right)$. The first fully developed Z-phases could already be detected by TEM after only 100 hours of exposure. A gradual Cr-enrichment was observed in some MX particles, which led to a composition in between MX and Z-phase (high $\mathrm{Cr}$ MX or low $\mathrm{Cr}$ $\mathrm{Z}$-phase). These precipitates were found in both $12 \mathrm{CrVNbN}$ and $9 \mathrm{CrVNbN}$ and were believed to be MX particles in the process of transforming into Z-phase by diffusion of $\mathrm{Cr}$ from the matrix into the MX particles. Two different types of transformation processes could be observed: the first generally for smaller precipitates, which showed a core-rim structure with a Cr-poor MX composition at the core, and a Cr-rich Z-phase at the rim with a smooth concentration gradient of $\mathrm{Cr}$ from the $\mathrm{MX}$ to $\mathrm{Z}$-phase area (see Figure 1(a)). These transforming precipitates are not necessarily symmetric and do not show any phase boundary between the core and rim. This $\mathrm{Cr}$ enrichment continues until the entire particle was transformed into Z-phase. More complicated forms of transformations could be seen in larger MX precipitates, most of which contained $\mathrm{Nb}$ cores, where distinct areas of $\mathrm{Z}$-phase will form at the edge of the MX particles. These Z-phase areas are typically be parallel (see Figure 1(b)), probably with a certain orientation relationship with the matrix. After the initial $\mathrm{Cr}$ in-diffusion, the parallel Z-phase areas will become well defined with sharp concentration gradients and could thus best be described as fully formed Z-phase attached to the MX. As this happens, the Z-phase starts to dissolve its MX host by matrix diffusion of $\mathrm{V}, \mathrm{Nb}$, and $\mathrm{N}$. This gives the transforming particle an $\mathrm{H}$ shape, two parallel $\mathrm{Z}$-phases connected by an MX bridge, until finally only two parallel Z-phases remain. ${ }^{[8]}$ Figure 2 shows atomic resolution imaging of one of the H-shaped particles. The tetragonal double layered structure of Z-phase can clearly be seen as there is a contrast between $\mathrm{Nb}$-containing $\mathrm{MX}$ layers and the $\mathrm{Cr}$ layers. The MX crystal structure appears monotonous as the $\mathrm{V} / \mathrm{Nb}$ atoms and any dissolved $\mathrm{Cr}$ occupy the same lattice sites. The two crystal structures are directly joined, as the atomic layers continue through the "phase boundary" (see Figure 2(a)). A closer investigation of the Z-phase double-layered structure shows it is still not fully ordered into a tetragonal crystal structure as some of the MX layers (bright layers) are present as triple layers (see Figure 2(b)). Layers are also observed to change brightness from MX contrast to $\mathrm{Cr}$ contrast, indicating the crystal structure is still rearranging itself.

Figure 3 shows XRD powder diffraction of the thermally aged $12 \mathrm{CrVNbN}$ alloy at three different temperatures. For graphical representation, the spectra are normalized to the highest intensity peak $\{111\}$ of $\mathrm{M}_{2} \mathrm{X}$ (except for $873 \mathrm{~K}\left[600{ }^{\circ} \mathrm{C}\right] / 30,000$ hours), as $\mathrm{M}_{2} \mathrm{X}$ was the most stable precipitate amongst the nitrides. The results from the thermal aging of the $9 \mathrm{CrVNbN}$ alloy are shown in Figure 4. As the Cr content is lower it contains fewer $\mathrm{Cr}$ nitrides and there is a peak overlap between $\mathrm{Cr}_{2} \mathrm{~N}$ and $(\mathrm{Nb}, \mathrm{V}) \mathrm{N}$, as lattice parameters for $\mathrm{MX}$ are slightly lower compared to the $12 \mathrm{CrVNbN}$
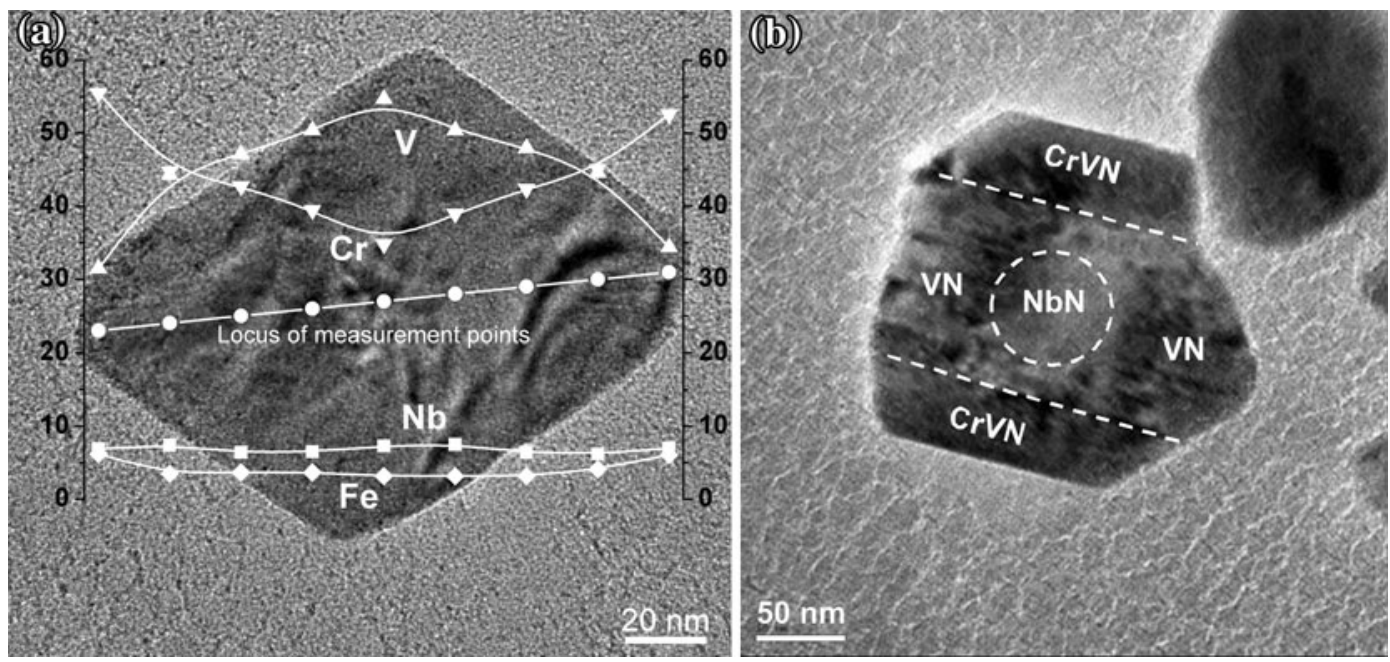

Fig. 1-Two typical transformation processes of small MX $(a)$ and large MX $(b)$ precipitates into Z-phase by in-diffusion of Cr in the $12 \mathrm{CrVNbN}$ alloy after exposure at $1000 \mathrm{~h} / 923 \mathrm{~K}\left(650^{\circ} \mathrm{C}\right) .{ }^{[8]}$ Scale in metallic at. pct. 

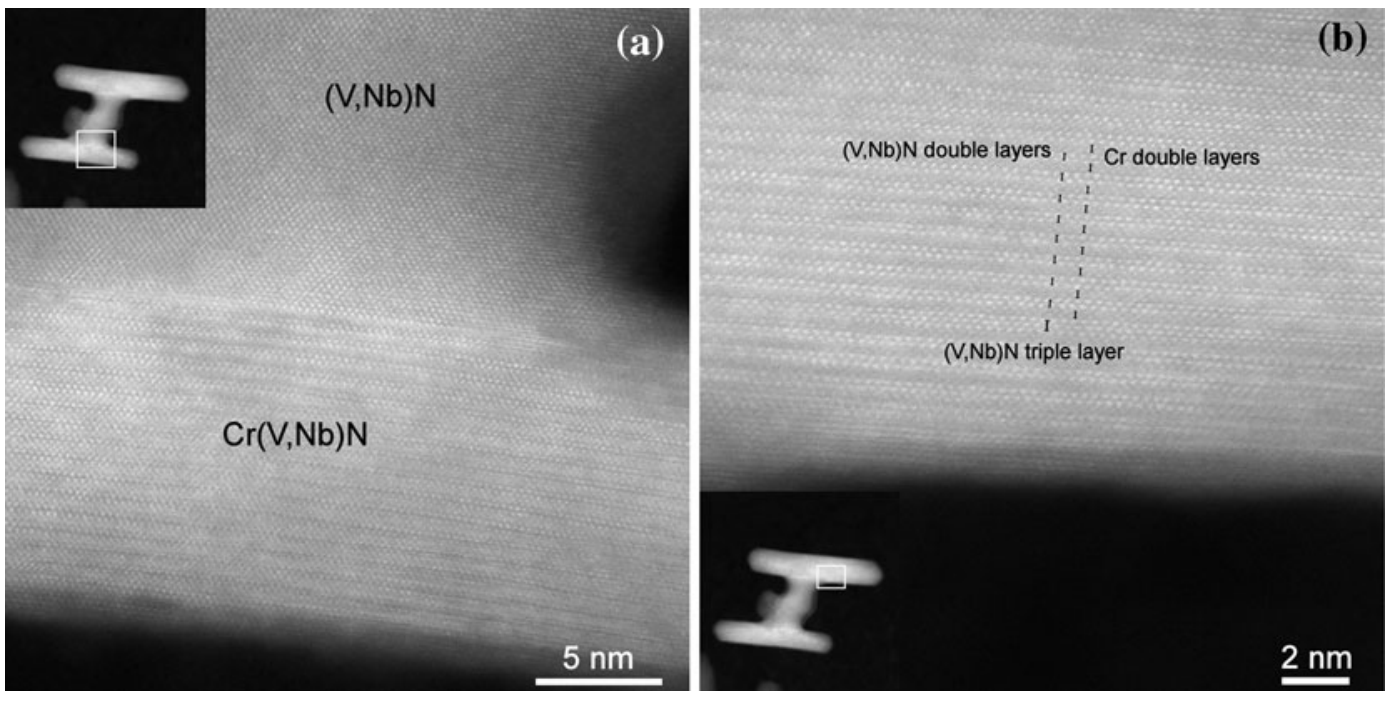

Fig. 2-HAADF atomic resolution imaging of an $\mathrm{H}$-shaped hybrid Z-phase/MX particle found in $12 \mathrm{CrVNbN}$ after exposure at $1000 \mathrm{~h} / 923 \mathrm{~K}$ $\left(650^{\circ} \mathrm{C}\right)$.

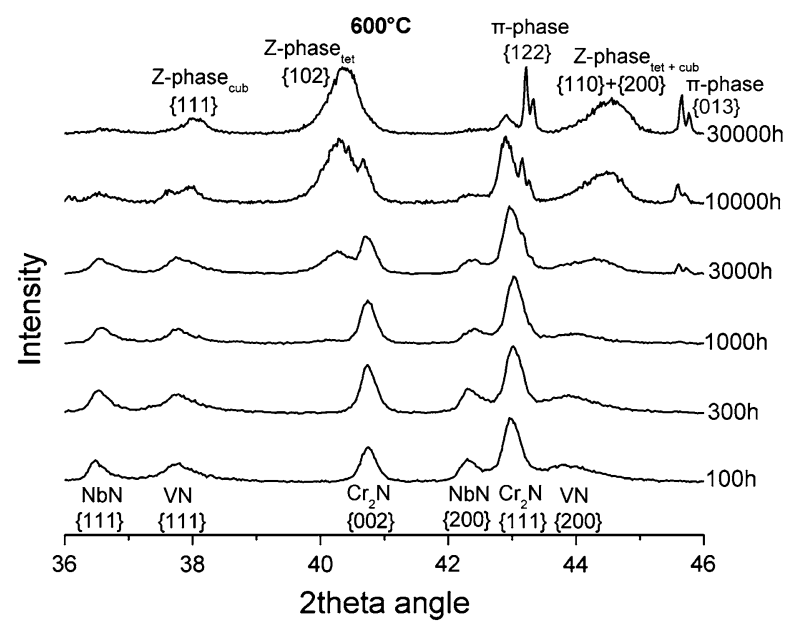

(a)

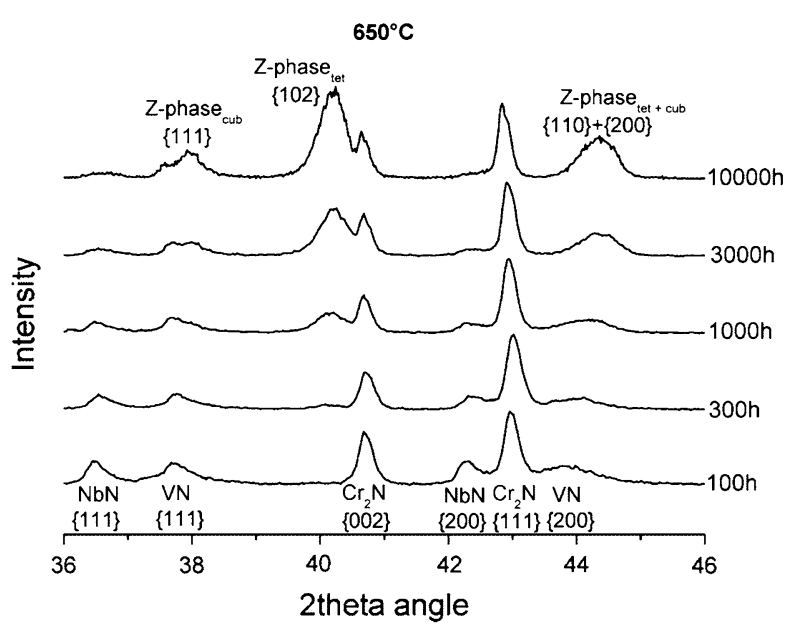

(b)

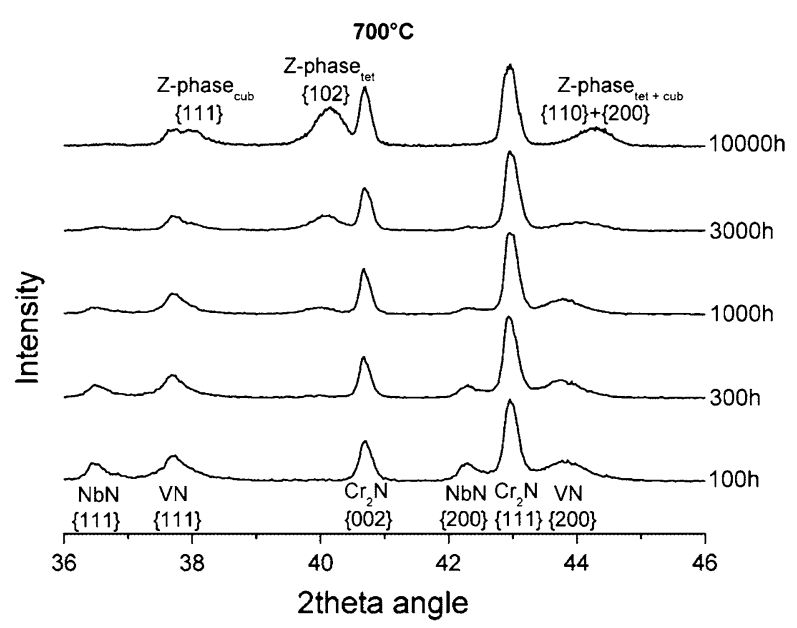

(c)

Fig. 3-XRD spectra of $12 \mathrm{CrVNbN}$ alloy isothermally aged at different times and temperatures. 


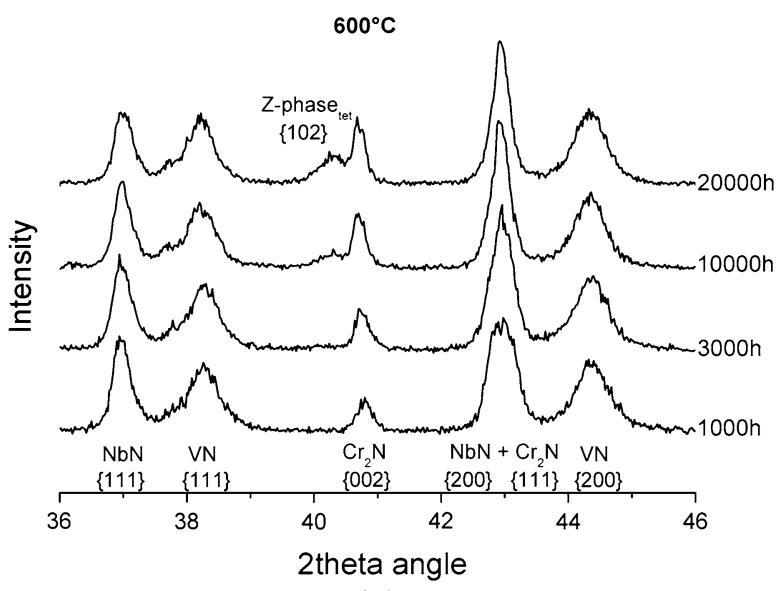

(a)

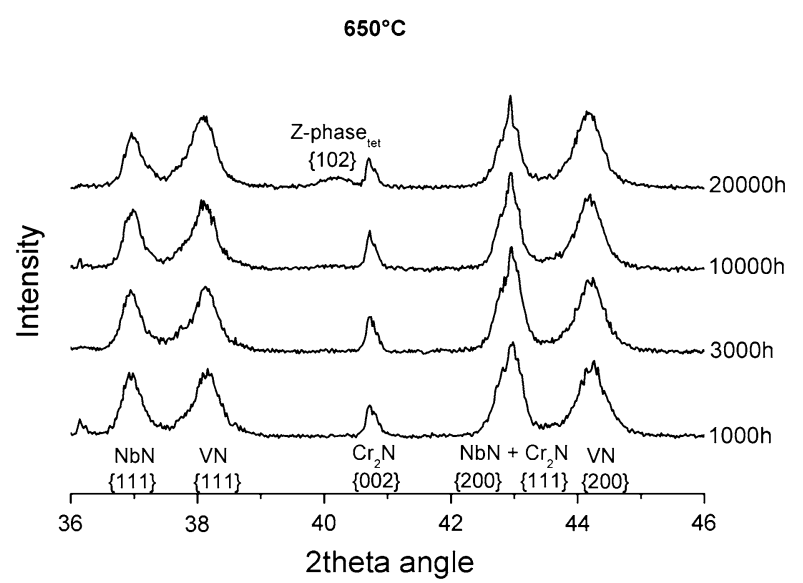

(b)

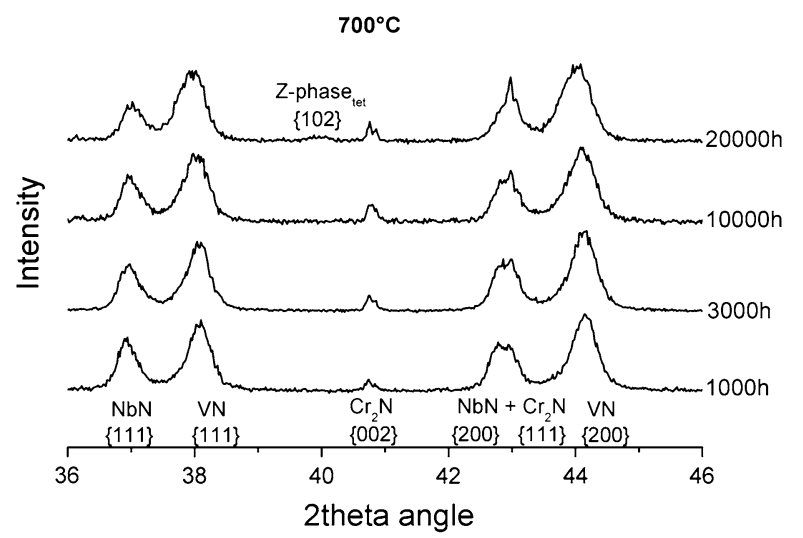

(c)

Fig. 4-XRD spectra of $9 \mathrm{CrVNbN}$ alloy isothermally aged at different times and temperatures.

Table II. Rietveld Refinement of the 12CrVNbN Spectra in Fig. 3, Values Shown in Vol Pct of Precipitates

\begin{tabular}{|c|c|c|c|c|c|c|c|}
\hline & $\pi$-phase & $\mathrm{Cr}_{2} \mathrm{~N}$ & $\mathrm{NbN}$ & $\mathrm{VN}$ & Z-Phase Cub & Z-Phase Tet & $\mathrm{Z} /(\mathrm{MX}+\mathrm{Z})(\mathrm{Pct})$ \\
\hline \multicolumn{8}{|c|}{$873 \mathrm{~K}\left(600^{\circ} \mathrm{C}\right)$} \\
\hline $100 \mathrm{~h}$ & 0.0 & 64.8 & 12.1 & 23.1 & 0.0 & 0.0 & 0 \\
\hline $300 \mathrm{~h}$ & 0.0 & 66.3 & 12.4 & 21.3 & 0.0 & 0.0 & 0 \\
\hline $1000 \mathrm{~h}$ & 1.2 & 66.6 & 12.1 & 14.0 & 0.0 & 6.2 & 19 \\
\hline $3000 \mathrm{~h}$ & 2.4 & 56.8 & 10.4 & 10.8 & 0.0 & 19.7 & 48 \\
\hline $10,000 \mathrm{~h}$ & 4.9 & 38.5 & 6.4 & 6.4 & 5.2 & 38.7 & 77 \\
\hline $30,000 \mathrm{~h}$ & 10.9 & 14.2 & 3.9 & 3.7 & 7.5 & 59.7 & 90 \\
\hline \multicolumn{8}{|c|}{$923 \mathrm{~K}\left(650^{\circ} \mathrm{C}\right)$} \\
\hline $100 \mathrm{~h}$ & & 64.7 & 13.1 & 22.2 & 0.0 & 0.0 & 0 \\
\hline $300 \mathrm{~h}$ & & 77.3 & 9.6 & 10.5 & 0.0 & 2.6 & 7 \\
\hline $1000 \mathrm{~h}$ & & 64.4 & 7.2 & 7.6 & 3.0 & 17.9 & 59 \\
\hline $3000 \mathrm{~h}$ & & 54.2 & 4.6 & 3.5 & 4.5 & 33.2 & 82 \\
\hline $10,000 \mathrm{~h}$ & & 37.0 & 2.6 & 0.0 & 13.9 & 46.5 & 96 \\
\hline \multicolumn{8}{|c|}{$973 \mathrm{~K}\left(700^{\circ} \mathrm{C}\right)$} \\
\hline $100 \mathrm{~h}$ & & 65.4 & 11.0 & 23.6 & 0.0 & 0.0 & 0 \\
\hline $300 \mathrm{~h}$ & & 70.9 & 8.4 & 19.8 & 0.0 & 0.9 & 3 \\
\hline $1000 \mathrm{~h}$ & & 75.0 & 5.0 & 12.2 & 0.0 & 7.8 & 31 \\
\hline $3000 \mathrm{~h}$ & & 75.9 & 2.7 & 3.9 & 2.5 & 15.0 & 73 \\
\hline $10,000 \mathrm{~h}$ & & 65.8 & 0.7 & 2.3 & 6.0 & 25.2 & 91 \\
\hline
\end{tabular}

alloy. Thus, the $\{200\}(\mathrm{V}, \mathrm{Nb}) \mathrm{N}$ peak has been used as a reference point because it does not overlap with other peaks and was relatively stable. A Rietveld refinement of the XRD spectra shown in Figures 3 and 4 was carried out to determine quantitatively the volume fractions of the extracted precipitates (see Tables II and III). 
Table III. Rietveld Refinement of the 9CrVNbN Spectra in Fig. 4, Values Shown in Vol Pct of Precipitates

\begin{tabular}{|c|c|c|c|c|c|c|}
\hline & $\mathrm{Cr}_{2} \mathrm{~N}$ & $\mathrm{NbN}$ & $\mathrm{VN}$ & Z-Phase Cub & Z-Phase Tet & $\mathrm{Z} /(\mathrm{MX}+\mathrm{Z})(\mathrm{Pct})$ \\
\hline \multicolumn{7}{|c|}{$873 \mathrm{~K}\left(600^{\circ} \mathrm{C}\right)$} \\
\hline $1000 \mathrm{~h}$ & 37.4 & 27.5 & 35.1 & 0.0 & 0.0 & 0 \\
\hline $3000 \mathrm{~h}$ & 38.7 & 27.0 & 31.5 & 0.0 & 2.7 & 4 \\
\hline $10,000 \mathrm{~h}$ & 39.5 & 24.1 & 27.9 & 0.0 & 8.5 & 14 \\
\hline $20,000 \mathrm{~h}$ & 37.6 & 22.2 & 27.1 & 0.0 & 13.1 & 21 \\
\hline \multicolumn{7}{|c|}{$923 \mathrm{~K}\left(650^{\circ} \mathrm{C}\right)$} \\
\hline $1000 \mathrm{~h}$ & 35.6 & 25.9 & 38.4 & 0.0 & 0.0 & 0 \\
\hline $3000 \mathrm{~h}$ & 35.3 & 25.5 & 38.1 & 0.0 & 1.1 & 2 \\
\hline $10,000 \mathrm{~h}$ & 34.5 & 22.2 & 39.2 & 0.0 & 4.1 & 6 \\
\hline $20,000 \mathrm{~h}$ & 30.5 & 21.1 & 40.9 & 0.0 & 7.5 & 11 \\
\hline \multicolumn{7}{|c|}{$973 \mathrm{~K}\left(700^{\circ} \mathrm{C}\right)$} \\
\hline $1000 \mathrm{~h}$ & 16.6 & 30.2 & 53.1 & 0.0 & 0.0 & 0 \\
\hline $3000 \mathrm{~h}$ & 19.5 & 27.0 & 53.4 & 0.0 & 0.0 & 0 \\
\hline $10,000 \mathrm{~h}$ & 18.5 & 24.4 & 54.8 & 0.0 & 2.3 & 3 \\
\hline $20,000 \mathrm{~h}$ & 18.4 & 20.3 & 57.0 & 0.0 & 4.3 & 5 \\
\hline
\end{tabular}

The main feature in the $12 \mathrm{CrVNbN}$ alloy is that with time, Z-phase peaks replace the MX peaks and, to some extent, $\mathbf{M}_{2} \mathrm{X}$. It can be seen that the main Z-phase peak (tetragonal peak at $40 \mathrm{deg} 2 \theta$ angle) is already visible after 300 hours at $923 \mathrm{~K}\left(650^{\circ} \mathrm{C}\right)$, signifying a fast Z-phase precipitation in this alloy. The presence of the Z-phase cubic crystal structure can be verified at all temperatures. As the V-rich MX transforms into Z-phase, a gradual shift in $\mathrm{VN}$ peak positions toward a lower lattice parameter corresponding to the cubic Z-phase takes place as $\mathrm{Cr}$ enter the VN, yielding fewer interstitial sites that are occupied by N. As Z-phase precipitation was expected to be slower in the $9 \mathrm{CrVNbN}$ alloy, longer aging times were used compared to the high Cr alloy. Only one Z-phase peak was clearly visible: the main tetragonal peak $\{102\}$ at about 40 deg $2 \theta$ angle. Even after 20,000 hours, the nitride population consists mainly of MX as the peak positions of VN have only barely started to move to cubic Z-phase positions $\left(873 \mathrm{~K}\left[600{ }^{\circ} \mathrm{C}\right]\right.$ specimens). It has previously been speculated that the cubic crystal structure of Z-phase is a metastable precursor phase for the tetragonal crystal structure, which has difficulty in nucleating. ${ }^{[5]}$ However, the data from the $12 \mathrm{CrVNbN}$ spectra show the amount of cubic Z-phase increases along with the amount of tetragonal Z-phase even in the range where Z-phase is well beyond the nucleation stage. For the $9 \mathrm{CrVNbN}$ alloy, the cubic Z-phase peak was too small to be quantified, as the Z-phase transformation has not progressed very far.

For the long-term exposed $12 \mathrm{CrVNbN}$ samples at $873 \mathrm{~K}\left(600{ }^{\circ} \mathrm{C}\right)$, a new precipitate appears with a A13 $\beta$-Mn crystal structure. This is believed to be $\pi$-phase nitride, which has a $\beta$-Mn filled crystal structure. ${ }^{11]} \mathrm{A}$ 30,000-hours sample was investigated to identify the new emerging phase. Very sharp XRD peaks could be observed, with the $\mathrm{K} \alpha_{1}$ and $\mathrm{K} \alpha_{2}$ peaks from the $\mathrm{Cu}$ radiation being individually distinguishable, indicating this phase being present as large particles. TEM investigations of the $873 \mathrm{~K}\left(600{ }^{\circ} \mathrm{C}\right) / 30,000$ hours sample show the presence of very large granular Cr-rich precipitates, average size of about $1 \mu \mathrm{m}$ (see Figure 5), with selected-area diffraction patterns corresponding to the emerging A13 peaks seen in the XRD spectra.

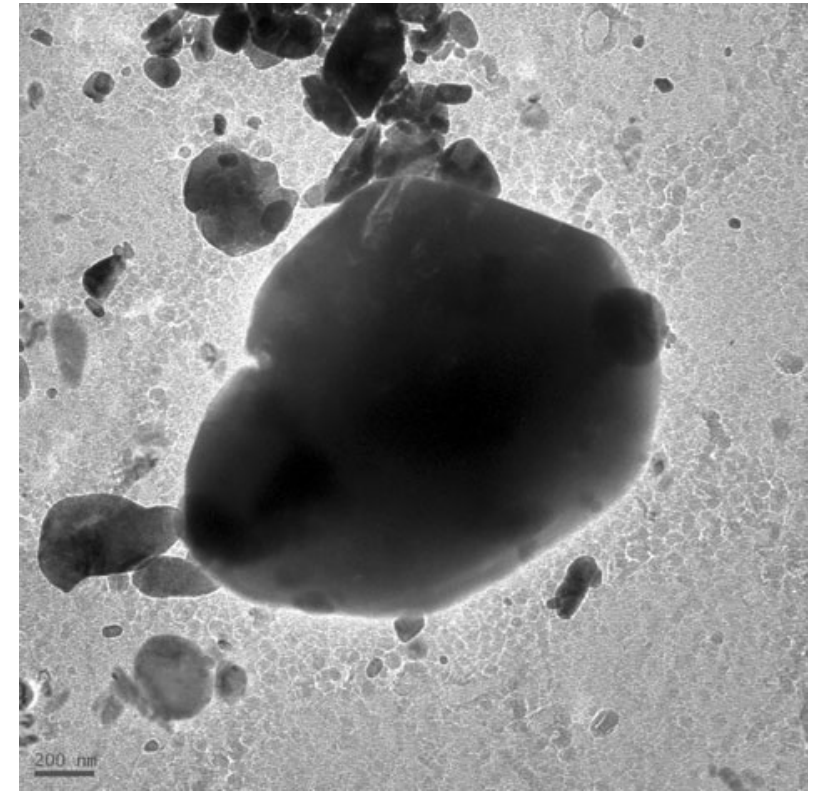

Fig. 5-A few very large particles believed to be $\pi$-phase were found among the other nitrides.

The precipitates had a chemical composition of $58 \mathrm{pct}$ Cr, 17 pet Fe, 10 pet Si, 9 pet Ni, 6 pet V (at. pet of metallic component), and a small amount of $\mathrm{N}$ could be identified using electron energy loss spectroscopy. According to the literature, ${ }^{[12,13]} \pi$-phase is found in austenitic steels with a composition of roughly $\mathrm{Cr}_{3}(\mathrm{Fe}, \mathrm{Ni})_{2} \mathrm{~N}$, which corresponds well with the composition found in this work, considering $12 \mathrm{CrVNbN}$ only contains 1.3 pct Ni. Rietveld refinement was calculated based on the chemical composition and an estimated lattice parameter of about $0.628 \mathrm{~nm}$. It shows an increase in quantity of $\pi$-phase with time, which probably will continue beyond 30,000 hours.

When comparing the $\mathrm{VN} / \mathrm{NbN}$ ratio between the two steels, the 9 pct $\mathrm{Cr}$ steel seems to contain a larger amount of Nb-rich MX. The peak positions for Nb-rich MX 
indicate a higher $\mathrm{V}$ content in 9 pct $\mathrm{Cr}$ steel, as they are closer to the VN peak positions, which could explain the increased amount. As the V-rich MX have a tendency to precipitate on the $\mathrm{Nb}$-rich $\mathrm{MX}$, forming particles with $\mathrm{Nb}$-rich core and V-rich shell (see Figure 1(b)), the EDS composition measurements are difficult to compare.

The $\mathrm{M}_{2} \mathrm{X}$ content is generally much higher for the $12 \mathrm{pct}$ $\mathrm{Cr}$ steel even though the $\mathrm{N}$ content is the same for both alloys. Thermodynamic simulations using Thermo-Calc TCFE6 database (Thermo-Calc, Stockholm, Sweden) show that $\mathrm{Cr}_{2} \mathrm{~N}$ becomes more stable with higher $\mathrm{Cr}$ contents at the expense of the MX nitrides. At high $\mathrm{Cr}$ levels, the $\mathrm{M}_{2} \mathrm{X}$ are stable to relatively high temperatures, while at low $\mathrm{Cr}$ levels, the dissolution temperature is close to the temperature range used in the current experiments. Thus, the $\mathrm{M}_{2} \mathrm{X}$ level is very sensitive to temperature in the 9 pct $\mathrm{Cr}$ steels, but less so in the $12 \mathrm{pct} \mathrm{Cr}$ steel. Experimental data on $12 \mathrm{CrVNbN}$ show that $\mathrm{M}_{2} \mathrm{X}$ amounts drop with time as the Z-phase becomes the dominant nitride, especially at lower temperatures. Calculations show at equilibrium conditions most $\mathrm{N}$ will be bound in the Z-phase, MX should be completely dissolved but a small $\mathrm{M}_{2} \mathrm{X}$ amount remains. This $\mathrm{M}_{2} \mathrm{X}$ amount is higher at $973 \mathrm{~K}\left(700^{\circ} \mathrm{C}\right)$ compared to $873 \mathrm{~K}\left(600{ }^{\circ} \mathrm{C}\right)$, suggesting Z-phase is comparatively more stable than $\mathrm{M}_{2} \mathrm{X}$ at a low temperature. These calculations do not take into account $\pi$-phase, and none of the thermally aged samples are believed to have reached equilibrium yet.

As the two model alloys are identical except for the $\mathrm{Cr}$ content, the results confirm the large effect of $\mathrm{Cr}$ on Z-phase precipitation speed seen in commercial steel grades. ${ }^{[3]}$ Thermodynamic calculations also show $\mathrm{Cr}$ to be the most important element, and this is the main difference between $\mathrm{Cr}(\mathrm{V}, \mathrm{Nb}) \mathrm{N}$ Z-phase and $(\mathrm{V}, \mathrm{Nb}) \mathrm{N}$ MX. ${ }^{[4]}$ The results show that the Z-phase precipitation speed is fastest at $923 \mathrm{~K}\left(650^{\circ} \mathrm{C}\right)$ for the $12 \mathrm{CrVNbN}$ alloy, which is consistent with time-temperature-precipitation (TTP) maps for Z-phase formation in 9 to 12 pct $\mathrm{Cr}$ commercial steels. ${ }^{[14]}$ The Z-phase precipitation is much slower in the $9 \mathrm{CrVNbN}$ alloy at all temperatures, but it occurs fastest at $873 \mathrm{~K}\left(600^{\circ} \mathrm{C}\right)$ compared to the other temperatures. The "nose" of the TTP diagram for 9 pct $\mathrm{Cr}$ steels is thus at a somewhat lower temperature than for 12 pct $\mathrm{Cr}$ steels. This corresponds well to thermodynamic calculations, which show Z-phase in low $\mathrm{Cr}$ steels to have a lower solution temperature, ${ }^{[4]}$ which would imply a displacement of the TPP diagram toward a lower temperature. However, this is not consistent with previous TTP maps for Z-phase formation in 9 pct $\mathrm{Cr}$ commercial steels based on presence/no presence measurements in TEM. ${ }^{[14]}$ The current work shows there might be an underestimation of Z-phase quantity in commercial 9 pct $\mathrm{Cr}$ steel grades if accelerated tests at $923 \mathrm{~K}\left(650{ }^{\circ} \mathrm{C}\right)$ are used.

The target temperature for the development of most experimental 9 to 12 pct $\mathrm{Cr}$ steels is $923 \mathrm{~K}\left(650^{\circ} \mathrm{C}\right)$ where the 12 pct $\mathrm{Cr}$ steel takes only little over 300 hours to reach the level of Z-phase precipitation that was obtained after 20,000 hours of exposure for the 9 pct $\mathrm{Cr}$ steel. At $873 \mathrm{~K}$ $\left(600{ }^{\circ} \mathrm{C}\right)$, which is the highest temperature at which power plants can operate today, the level of Z-phase in the 20,000hours 9 pct $\mathrm{Cr}$ sample corresponds to the 1000-hours 12 pct $\mathrm{Cr}$ sample. Thus, in the $873 \mathrm{~K}$ to $923 \mathrm{~K}\left(600{ }^{\circ} \mathrm{C}\right.$ to $650^{\circ} \mathrm{C}$ ) temperature range, the Z-phase precipitation speed is 20 to 50 times faster in the $12 \mathrm{pct} \mathrm{Cr}$ alloy to reach 10 to 20 pct precipitation (depending on the temperature). The data from the Rietveld refinement in Tables II and III have been plotted in Figure 6, where TTP diagrams for Z-phase precipitation have been estimated for both alloys, respectively, based on the amount of MX transformed into Z-phase. The "nose" of the 9 pct $\mathrm{Cr}$ curve is hard to estimate without having data for $823 \mathrm{~K}$ $\left(550{ }^{\circ} \mathrm{C}\right)$; thus, it could be lower than shown in Figure 6 . Note that the data in Figure 6 cannot directly be correlated to commercial 9 and 12 pct Cr steels, as these steels contain about 0.1 wt pet $\mathrm{C}$. Because carbon reacts with $\mathrm{Cr}$ to form carbides, the $\mathrm{Cr}$ content in the matrix is reduced by about 1 pct. Thus, the TTP diagrams in Figure 6 should represent 10 pct $\mathrm{Cr}$ and 13 pet $\mathrm{Cr}$ carbon-containing commercial grades. It must also be taken into account that newer experimental/commercial steels may also contain elements such as Co, which increases the precipitation speed of Z-phase, ${ }^{[15,16]}$ and the current model alloys contains a relative large amount of nickel, which is considered to accelerate Z-phase precipitation speed. ${ }^{[17]}$

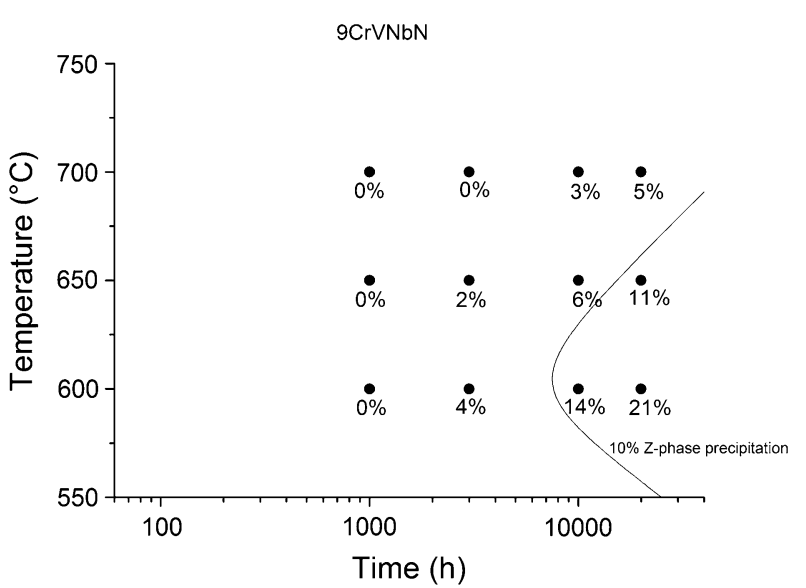

(b)

Fig. 6-TTP curves of the amount of MX transformed into Z-phase estimated from the Rietveld data. 


\section{CONCLUSIONS}

Z-phase precipitation speed was quantitatively investigated in a $12 \mathrm{CrVNbN}$ and a $9 \mathrm{CrVNbN}$ alloy, which were identical except for the $\mathrm{Cr}$ content. Z-phase precipitation speed in the $12 \mathrm{pct} \mathrm{Cr}$ alloy was found to be fastest at $923 \mathrm{~K}\left(650^{\circ} \mathrm{C}\right)$, while for the 9 pet Cr alloy, it was fastest at $873 \mathrm{~K}\left(600{ }^{\circ} \mathrm{C}\right)$. Comparing the XRD spectra of the two model alloys quantitatively shows that the Z-phase precipitation speed is about 20 times faster at $873 \mathrm{~K}\left(600^{\circ} \mathrm{C}\right)$ in the 12 pet $\mathrm{Cr}$ alloy compared to the 9 pet $\mathrm{Cr}$ alloy and about 50 times faster at $923 \mathrm{~K}$ $\left(650^{\circ} \mathrm{C}\right)$. During the transformation to Z-phase, the VN XRD peaks can be seen shifting from the $(\mathrm{V}, \mathrm{Nb}) \mathrm{N}$ positions toward the $\mathrm{Cr}(\mathrm{V}, \mathrm{Nb}) \mathrm{N}$ positions, indicating a physical transformation of MX to Z-phase. Atomic resolution imaging showed the MX and Z-phase areas of particles were joined and that the crystal structure of the Z-phase was not fully ordered.

During long-term exposure at $873 \mathrm{~K}\left(600{ }^{\circ} \mathrm{C}\right)$ of the $12 \mathrm{CrVNbN}$ alloy, precipitation of what is believed to be the $\pi$-phase occurs. To the authors' knowledge, the $\pi$-phase has not been observed in this type of steel before.

\section{ACKNOWLEDGMENTS}

Financial support from the Danish Research Council for Independent Research-Production and Technology Sciences (grant 10-093690) is gratefully acknowledged.

\section{REFERENCES}

1. E. Schnabel, P. Shcwaab, and H. Weber: Stahl und Eisen, 1987, vol. 197, pp. 691-96.

2. A. Strang and V. Vodarek: Mater. Sci. Technol., 1996, vol. 12, pp. 552-56.

3. H.K. Danielsen and J. Hald: Energy Mater., 2006, vol. 1, pp. 4957.

4. H.K. Danielsen and J. Hald: CALPHAD, 2007, vol. 31, pp. 50514.

5. H.K. Danielsen and J. Hald: Mater. Sci. Eng. A, 2009, vol. 505, pp. 169-77.

6. K. Sawada, H. Kushima, M. Tabuchi, and K. Kimura: Mater. Sci. Eng. A, 2011, vol. 528, pp. 5511-18.

7. P.E. di Nunzio, L. Cipolla, S. Tiberi Vipraio, S. Martelli, and M.A.J. Somers: Mater. Sci. Technol., 2010, vol. 26, pp. 1423-28.

8. L. Cipolla, H.K. Danielsen, D. Venditti, P.E. di Nunzio, J. Hald, and M.A.J. Somers: Acta Mater, 2010, vol. 50, pp. 669-79.

9. H.K. Danielsen, J. Hald, and M.A.J. Somers: Scripta Metall, 2012, vol. 66, pp. 261-64.

10. H.K. Danielsen, J. Hald, F.B. Grumsen, and M.A.J. Somers: Metall. Mater. Trans. A, 2006, vol. 37A, pp. 2633-40.

11. T.J. Prior and P.D. Battle: J. Solid State Chem., 2003, vol. 172, pp. 138-47.

12. M. Kikuchi, T. Sekita, S. Wakita, and R. Tanaka: ISIJ, 1981, vol. 67 , pp. 1981-89.

13. T. Sourmail: Mater. Sci. Technol., 2001, vol. 17, pp. 1-14.

14. K. Sawada, H. Kushima, K. Kimura, and M. Tabuchi: ISIJ Int., 2007, vol. 47, pp. 733-39.

15. L. Helis, Y. Toda, T. Hara, H. Miyazaki, and F. Abe: 34th MPA Seminar, Stuttgart, Germany, 2008, pp. 9.1-9.20.

16. F. Kauffmann, G. Zies, K. Maile, S. Straub, and K.H. Mayer: 34th MPA Seminar, Stuttgart, Germany, 2008, pp. 4.1-4.14.

17. V. Vodarek and A. Strang: Materials for Advanced Power Engineering, Forschnungszentrum Jülich $\mathrm{GmbH}$, Jülich, Germany, 2002, pp. 1223-32. 